\title{
Clinical Study \\ Sexual Well-Being in Adult Male Patients with Congenital Adrenal Hyperplasia
}

\author{
Bogna Dudzińska, Jonas Leubner, Manfred Ventz, and Marcus Quinkler \\ Clinical Endocrinology, Charité Campus Mitte, Charité University Medicine Berlin, Charitéplatz 1, 10117 Berlin, Germany \\ Correspondence should be addressed to Marcus Quinkler; marcus.quinkler@charite.de
}

Received 5 September 2013; Revised 17 December 2013; Accepted 21 December 2013; Published 10 February 2014

Academic Editor: Małgorzata Kotula-Balak

Copyright (C) 2014 Bogna Dudzińska et al. This is an open access article distributed under the Creative Commons Attribution License, which permits unrestricted use, distribution, and reproduction in any medium, provided the original work is properly cited.

\begin{abstract}
Introduction. Men with congenital adrenal hyperplasia (CAH) due to 21-hydroxylase deficiency show impaired fecundity due to testicular adrenal rest tumors and/or suppression of the gonadal axis. Sexual well-being might be an additional factor; however, no data exists. Patients and Methods. Prospective longitudinal monocentric study included 20 male CAH patients (14 salt wasting, 6 simple virilizing; age 18-49 yr). Clinical assessment, testicular ultrasound, biochemical and hormonal parameters, three validated self-assessment questionnaires (SF-36, GBB-24, and HADS), and male Brief Sexual Function Inventory (BSFI) were analyzed at baseline and after two years. Results. Basal LH and testosterone levels suggested normal testicular function. LH and FSH responses to $\mathrm{GnRH}$ were more pronounced in patients with a good therapy control according to androstenedione/testosterone ratio $<0.2$. This group had significant higher percentage of patients on dexamethasone medication. GBB-24, HADS, and SF-36 showed impaired $z$ scores and no changes at follow-up. BSFI revealed impairments in dimensions "sexual drive," "erections," and "ejaculations," whereas "problem assessment" and "overall satisfaction" revealed normal $z$-scores. Androstenedione levels correlated $(P=0.036)$ inversely with $z$-scores for "sexual drive" with higher levels associated with impaired "sexual drive." Conclusion. Male CAH patients showed a partly impaired sexual well-being which might be an additional factor for reduced fecundity.
\end{abstract}

\section{Introduction}

Fecundity is reduced in male patients with congenital adrenal hyperplasia (CAH) due to 21-hydroxylase deficiency. Recent studies suggested that development of testicular adrenal rest tumors (TARTs), which cause an obstruction of the seminiferous tubules, may play a major role $[1,2]$. In addition, suppression of the gonadal axis due to adrenal androgen excess might also cause reduced fertility [2]. Both pathomechanisms are thought to be a consequence of insufficient hormonal control [3].

Besides these somatic causes of impaired fertility in $\mathrm{CAH}$ males, there might be aspects of psychosocial adaption and sexual well-being which may be additional factors for impaired fertility. However, up to now there are no studies investigating sexual well-being in male $\mathrm{CAH}$ patients. Sexual function is best measured by patient self-report avoiding interviewer bias and only patients can report on issues such as sexual interest and the extent to which sexual dysfunction has an adverse effect on their quality of life [4]. The Brief Sexual Function Inventory (BSFI) provides an excellent tool to assess a self-reported measure of current sexual functioning [4].

The aims of our two-year prospective study in adult male patients with congenital adrenal hyperplasia were

(1) to investigate changes in hypothalamic-pituitarytesticular regulation by $\mathrm{GnRH}$ testing,

(2) to evaluate changes in sexual functioning and quality of life.

\section{Methods}

2.1. Patient Population. The subjects were adult male patients with confirmed classical CAH due to 21-hydroxylase deficiency with regular hormonal follow-up at the outpatient clinic of the Department of Endocrinology of the Charite Campus Mitte Hospital, Berlin. The study was approved by the ethics committee of the Charité Campus Mitte Berlin 
(permit no. ES1/037/06). All subjects gave written informed consent. For individual patient characteristics, see Table 1. Exclusion criteria were other diseases with impairment of gonadal capacity and other general and psychiatric diseases.

All patients were seen at the outpatient clinic by two experienced endocrinologists (M.Q.; M.V.) on a regular basis every six months. In each patient physical examination, blood drawings (between 0800 and 1000 h, 2 h after morning medication), questionnaires, and testicular ultrasounds were performed at study start (baseline) and two years later (follow-up). The treating physicians tried to optimize treatment during the study period according to the Endocrine Practice guidelines [5].

The standard medications for the treatment of 21-OHD deficiency are hydrocortisone (HC), prednisolone (PR), and dexamethasone (DX) $[6,7]$. Since these glucocorticoids have different biological strengths, dosage for PR and DX were converted into hydrocortisone equivalent (PR was converted 1 to 5 to $\mathrm{HC}, \mathrm{DX} 1$ to 70 to $\mathrm{HC})[8,9]$. After conversion to the hydrocortisone equivalent dose, the daily total amount of hydrocortisone equivalent in milligrams was calculated as well as the total daily dose per body surface area $\left(\mathrm{mg} / \mathrm{m}^{2}\right)$.

2.2. Testicular Imaging. Grey-scale and color Doppler ultrasonography of the testes was obtained in longitudinal and transverse sections.

2.3. Hormone Measurements. Circulating concentrations of $\Delta 4$-androstenedione (AD) (BeckmannCoulter, Krefeld, Germany), testosterone, DHEAS (DPC Biermann GmbH; Bad Nauheim, Germany), LH, FSH, renin concentrations, ACTH, and 17-hydroxy-progesterone (17-OHP) (MP Biomedicals $\mathrm{GmbH}$; Eschwege, Germany) were measured by commercially available assays. The GnRH stimulation test was performed by administering $100 \mu \mathrm{g}$ GnRH (Aventis Pharma $\mathrm{GmbH}$, Frankfurt, Germany) as an i.v.bolus. Serum FSH and $\mathrm{LH}$ levels were measured at 0 and $30 \mathrm{~min}$ after $\mathrm{GnRH}$ dose. We used the differences between peak and basal LH and FSH concentrations, referred to as $\Delta \max$, as response variables to eliminate the additive effect of basal LH or FSH level on the peak [10]. A normal LH response in GnRH testing was assumed if LH levels rise was at least 3-fold; normal FSH response if $\mathrm{FSH}$ rises was at least $50 \%$ or above $3 \mathrm{IU} / \mathrm{L}$.

2.4. Questionnaires. Patients were asked to complete four different questionnaires. Psychometric evaluation of patients was performed using three validated self-assessment subjective health status (SHS) questionnaires: the SF-36, the brief form of the Giessen Complaint List (GBB-24), and the "Hospital Anxiety and Depression Scale" (HADS). In addition, the sexual functioning was assessed by the male Brief Sexual Function Inventory (BSFI). All four questionnaires were presented as self-explanatory, multiple-choice self-assessments.

The SF-36 questionnaire is the most widely used generic instrument to assess Quality of Life (QoL) [11]. It consists of eight multi-item domains representing physical functioning $(\mathrm{PF})$, role functioning physical (RP), bodily pain (BP), general health perception $(\mathrm{GH})$, vitality (VT), social functioning $(\mathrm{SF})$, role functioning emotional (RE), and mental health
$(\mathrm{MH})$. The domain scores range from 0 to 100 with higher values indicating better QoL $[12,13]$.

The HADS measures in 14 items anxiety and depression in physically ill individuals [14]. Each item is scored as a number, with a maximum score of 21 for each subscale. Higher scores indicate higher levels of anxiety or depression. A cut-off value of 8 is regarded as indicating mild impairment, and a cut-off value of 11 is indicative of severe impairment.

The short form of the GBB-24 questionnaire consists of 24 items defining four subscales (exhaustion tendency, gastric symptoms, pain in the limbs, and heart complaints), each including six items with ratings from 0 to 4 . In addition, a global score of discomfort (GSD) is calculated by adding the four subscale scores. The maximum value for each subscale is 24, and for the global score 96. Higher scores indicate greater impairment of well-being [15].

Regarding control group data we calculated the $z$-scores by using reference data for SF-36 scores obtained from the German National Health Survey (Bundesgesundheits-Survey 1998, Robert Koch Institut, Berlin 2000, public use file BGS 98) comprising a representative random sample of 7124 subjects from the German population aged between 18 and 79 yr. Reference data for the HADS $(n=4410)$ and the GBB$24(n=2076)$ were obtained from previously performed surveys [15-17].

The Brief Sexual Function Inventory (BSFI) was used to assess perceived problems associated with sexual drive (two items), erection (three items), problem assessment (three items), ejaculation (two items), or overall satisfaction (one item). Each question was scored on a 5-point scale, ranging from 0 to 4 , with lower scores indicating worse sexual function [4]. This questionnaire is useful for measuring male sexual function in practice and research. Regarding control group data we calculated the $z$-scores by using normative data for the BSFI obtained from a representative random sample of 1185 subjects from the Norwegian population aged between 20 and 79 yr [18].

2.5. Statistical Analysis. Variables were assessed for normality by Kolmogorov-Smirnov test. Results are expressed as mean \pm standard deviation (SD) if not stated otherwise. The significance of data was determined by Students $t$ test in normally distributed and in not normally distributed data by MannWhitney-Wilcoxon test where appropriate. In addition, Pearson's correlation was performed. A $P$ value less than 0.05 was regarded as significant. Statistical analysis was performed using SPSS for Windows 15.0 (SPSS, Inc., Chicago, IL).

\section{Results}

At baseline 28 adult male patients with $\mathrm{CAH}$ were screened for study inclusion. Eight patients were excluded due to testicular operations or other exclusion criteria. Finally 20 patients were enrolled into the study. Three patients did not participate in the 2-year follow-up visit and were not included into the 2-year follow-up analysis.

Clinical and genetic characteristics are shown in Table 1: 14 patients had salt-wasting $\mathrm{CAH}$ and 6 patients had simplevirilizing $\mathrm{CAH}$. The mean age was $28.9 \pm 10.5$ years. Patients 
TABLE 1: Clinical and genetic characteristics of 20 male patients with 21-OHD at study start (baseline).

\begin{tabular}{|c|c|c|c|c|c|c|c|c|}
\hline Pat. no. & $\begin{array}{l}\text { Pheno- } \\
\text { type }\end{array}$ & Genotype & $\begin{array}{l}\text { Mutation } \\
\text { group }\end{array}$ & Age (yr) & BMI $\left(\mathrm{kg} / \mathrm{m}^{2}\right)$ & Height $(\mathrm{cm})$ & $\begin{array}{c}\text { GC dose } \\
\text { equivalent } / \mathrm{m}^{2} \\
\text { BSA }\left(\mathrm{mg} / \mathrm{m}^{2}\right)\end{array}$ & $\begin{array}{l}\text { FC dose } / \mathrm{m}^{2} \\
\mathrm{BSA}\left(\mu \mathrm{g} / \mathrm{m}^{2}\right)\end{array}$ \\
\hline B02 & SW & $\mathrm{I} 2 \mathrm{G} / \mathrm{I} 172 \mathrm{~N}$ & B & 23 & 19.0 & 178 & 14.52 & 58.07 \\
\hline B06 & SW & $\mathrm{I} 2 \mathrm{G}+\mathrm{P} 453 / \mathrm{I} 2 \mathrm{G}+\mathrm{P} 453 \mathrm{~S}$ & B & 24 & 23.0 & 164 & 22.29 & 63.69 \\
\hline B09 & SW & V281L/del + V281L & nc & 18 & 16.5 & 171 & 33.33 & 66.67 \\
\hline B10 & SW & $\mathrm{I} 172 \mathrm{~N} / \mathrm{I} 172 \mathrm{~N}$ & $\mathrm{~B}$ & 18 & 26.0 & 170 & 15.79 & 52.63 \\
\hline B12 & SW & $\mathrm{I} 2 \mathrm{G} / \mathrm{I} 2 \mathrm{G}$ & A & 32 & 28.0 & 184 & 19.91 & 88.50 \\
\hline B14 & SW & I2G/del & A & 25 & 27.5 & 177 & 14.63 & 48.78 \\
\hline B15 & SW & $\mathrm{I} 2 \mathrm{G} / \mathrm{I} 2 \mathrm{G}$ & A & 21 & 26.5 & 163 & 19.44 & 55.56 \\
\hline B16 & SW & I2G/del & A & 23 & 25.0 & 170 & 27.78 & 55.56 \\
\hline B17 & SW & I2G/del & A & 20 & 30.0 & 171 & 26.83 & 48.78 \\
\hline B18 & SW & I172/del & $\mathrm{B}$ & 49 & 25.0 & 155 & 20.22 & 37.37 \\
\hline B20 & SW & nd & & 18 & 20.0 & 174 & 13.24 & 58.82 \\
\hline B07 & SW & del/R356W & Null & 23 & 28.0 & 172 & 17.68 & 50.50 \\
\hline B08 & SW & I2G-V281L/del-V281L & A & 29 & 25.5 & 160 & 13.24 & 58.86 \\
\hline B22 & SW & I2G/E6 cluster & A & 23 & 25.0 & 180 & 20.0 & 50.00 \\
\hline B01 & SV & $\mathrm{I} 2 \mathrm{G} / \mathrm{I} 172 \mathrm{G}$ & $\mathrm{B}$ & 42 & 36.0 & 158 & 10.01 & \\
\hline B03 & SV & $\mathrm{I} 172 \mathrm{~N} / \mathrm{I} 172 \mathrm{~N}+\mathrm{del}$ & B & 47 & 27.0 & 153 & 16.68 & \\
\hline B04 & SV & $\mathrm{I} 2 \mathrm{G} / 172 \mathrm{~N}$ & B & 42 & 24.0 & 153 & 19.61 & \\
\hline $\mathrm{B} 13$ & SV & $\mathrm{I} 172 \mathrm{~N} / \mathrm{Q} 318 \mathrm{X}+\mathrm{V} 281 \mathrm{~L}$ & B & 26 & 38.0 & 172 & 20.30 & \\
\hline B19 & SV & I172N/del & B & 47 & 30.0 & 162 & 19.95 & \\
\hline \multirow[t]{4}{*}{ B21 } & SV & $\mathrm{I} 2 \mathrm{G} / \mathrm{I} 172 \mathrm{~N}$ & B & 28 & 24.0 & 164 & 22.59 & \\
\hline & & SW Mean \pm SD & & $24.7 \pm 8.1$ & $24.6 \pm 3.8$ & $170.6 \pm 8.0$ & $19.92 \pm 5.97$ & $56.70 \pm 11.68$ \\
\hline & & SV Mean \pm SD & & $38.7 \pm 9.3$ & $29.8 \pm 6.0$ & $160.3 \pm 3.0$ & $18.19 \pm 4.43$ & \\
\hline & & All CAH Mean \pm SD & & $28.9 \pm 10.5$ & $26.2 \pm 5.0$ & $167.6 \pm 9.0$ & $19.40 \pm 5.50$ & \\
\hline
\end{tabular}

SW: classical salt wasting; SV: classical simple virilizing; BMI: body mass index; BSA: body surface area; FC: fludrocortisone. The dose of daily glucocorticoid (GC) was converted into milligrams of daily hydrocortisone equivalent ( $1 \mathrm{mg}$ dexamethasone $=14 \mathrm{mg}$ prednisolone $=70 \mathrm{mg}$ hydrocortisone). Mutation grouping was done according to Krone et al. [30]; nc: not classified; nd: not done.

with salt-wasting $\mathrm{CAH}$ were diagnosed within the first week after birth; patients with simple-virilizing form were diagnosed in the first 7 years after birth.

Biochemical and hormonal parameters of the 17 patients at baseline and at the 2-year follow-up visit are presented in Table 2. Over the study period BMI, systolic blood pressure, lipids, androgens, and androgen precursors did not change significantly in the whole cohort or in the SW and SV subgroups. Only diastolic blood pressure was significantly lower at the 2-year follow-up. The daily HC equivalent dose did not decrease significantly. Information about fatherhood was available in 16 of the 17 men studied. Of these, two were fathers (12.5\%), one of one child and the other of two children.

3.1. Adrenal Crisis. During the study period three adrenal crises occurred resulting in a calculated incidence of 8.8 adrenal crises per 100 patients/year, which is higher than the recently reported frequency in $\mathrm{CAH}$ patients $(4.8$ crises per 100 patients/year) [19] and resembles more the frequency in patients with primary adrenal insufficiency $(6.6$ crises per 100 patients/year) [20].
3.2. Hormonal Control. Decreased DHEAS levels were measured in 15 patients $(88.2 \%)$ at baseline and in all patients at follow-up (100\%). Poor therapy control with elevated serum 4-androstenedione levels ( $>10 \mathrm{nmol} / \mathrm{L}$ ) was observed in no patients at baseline $(0 \%)$ and in only one patient $(5.9 \%)$ at follow-up, whereas elevated levels of 17-OHP in serum ( $>36 \mathrm{nmol} / \mathrm{L})$ were present in 4 patients $(23.5 \%)$ at baseline and 2 patients at follow-up (11.8\%). The androstenedione to testosterone $(\mathrm{AD} / \mathrm{T})$ ratio as indicator of testicular testosterone production was normal $(<0.2)$ in 11 patients $(64.7 \%)$ at baseline and follow-up; three patients (17.6\%) had an $\mathrm{AD} / \mathrm{T}$ ratio $>1$ suggesting testosterone from predominantly adrenal origin (Table 2). Estradiol levels were within the normal male range ruling out any suppression of the hypothalamuspituitary-gonadal axis by estradiol.

3.3. Gonadotropic Axis. Total testosterone levels were decreased in 4 patients $(23.5 \%)$ at baseline and in 2 patients (11.8\%) at follow-up; calculated free testosterone index was diminished in 5 patients $(29.4 \%)$ at baseline and in 8 patients $(47.1 \%)$ at follow-up. Basal LH levels were normal 
TABLE 2: Biochemical and hormonal parameters in 17 male patients with 21-OHD at study start (baseline) and after 2-year follow-up.

\begin{tabular}{|c|c|c|}
\hline & Baseline & Follow-up \\
\hline BMI $\left(\mathrm{kg} / \mathrm{m}^{2}\right)$ & $26.2 \pm 5.5(16.5-38)$ & $25.5 \pm 5.6(19-38.5)$ \\
\hline BP systolic/diastolic (mmHg) & $118 / 78 \pm 12 / 8(100-135 / 60-90)$ & $117 / 73^{*} \pm 17 / 10(90-145 / 60-90)$ \\
\hline Potassium (mmol/L) & $3.76 \pm 0.43(3.2-4.7)$ & $3.92 \pm 0.34(3.4-4.6)$ \\
\hline Sodium (mmol/L) & $140.8 \pm 1.8(136-144)$ & $139.5 \pm 2.7(134-143)$ \\
\hline Cholesterol (mg/dL) & $169 \pm 36(126-237)$ & $185 \pm 43(106-247)$ \\
\hline Triglycerides (mg/dL) & $103 \pm 57(44-219)$ & $116 \pm 62(48-256)$ \\
\hline ACTH $(\mathrm{pg} / \mathrm{mL})$ & $153 \pm 331(5-1250)$ & $62 \pm 141(5-561)$ \\
\hline 17-OHP (ng/mL) & $14.9 \pm 18.8(0.8-50)$ & $25.2 \pm 58.8(0.8-218)$ \\
\hline Androstenedione (ng/mL) & $1.55 \pm 2.39(0.2-10)$ & $1.85 \pm 3.15(0.2-10.4)$ \\
\hline DHEAS (ng/mL) & $620 \pm 778(90-3395)$ & $442 \pm 378(1-1246)$ \\
\hline Testosterone (ng/mL) & $5.0 \pm 2.6(1.7-9.6)$ & $4.4 \pm 2.6(1.5-9.5)$ \\
\hline SHBG (nmol/L) & $41 \pm 20(14-77)$ & $44 \pm 25(12-99)$ \\
\hline Free testosterone index & $46.3 \pm 20.5(15.4-100.6)$ & $40.1 \pm 24.4(7.3-113.8)$ \\
\hline $\mathrm{AD} / \mathrm{T}$ ratio & $0.41 \pm 0.57(0.06-1.96)$ & $0.45 \pm 0.81(0.06-3.26)$ \\
\hline Estradiol (pg/mL) & $26.6 \pm 8.0(15.6-41.1)$ & $21.8 \pm 12.2(5.0-49.5)$ \\
\hline $\operatorname{Renin}(\mathrm{ng} / \mathrm{L})^{\S}$ & $84.3 \pm 130.7(2.5-330)$ & $288.7 \pm 767.7(2.5-2592)$ \\
\hline LH basal (U/L) & $4.1 \pm 2.2(1.5-8.9)$ & $3.8 \pm 2.9(0.6-7.9)$ \\
\hline LH peak (U/L) & $31.9 \pm 12.3(13.5-61.3)$ & $25.7 \pm 16.8(0.8-53.4)$ \\
\hline$\Delta \max \mathrm{LH}$ & $27.8 \pm 11.1(7.9-53.6)$ & $22.0 \pm 15.5(0.3-46.2)$ \\
\hline FSH basal (U/L) & $7.1 \pm 6.8(2.3-28.9)$ & $6.1 \pm 4.0(1.9-12.9)$ \\
\hline FSH peak (U/L) & $12.9 \pm 11.1(4.4-46)$ & $9.5 \pm 8.5(1.0-26.2)$ \\
\hline$\Delta \max F S H$ & $5.9 \pm 4.8(0.6-17.1)$ & $4.3 \pm 4.5(1.0-13.3)$ \\
\hline $\begin{array}{l}\text { Daily GC equivalent dose } / \mathrm{m}^{2} \\
\text { BSA }\left(\mathrm{mg} / \mathrm{m}^{2}\right)\end{array}$ & $19.8 \pm 5.8(10.0-33.3)$ & $18.6 \pm 6.9(9.2-30.6)$ \\
\hline
\end{tabular}

Data are means \pm SD (range). BMI: body mass index; BP: blood pressure; BSA: body surface area. Normal ranges (SI units shown in brackets): sodium 134$145 \mathrm{mmol} / \mathrm{L}$; potassium $3.4-5.2 \mathrm{mmol} / \mathrm{L}$; cholesterol < $200 \mathrm{mg} / \mathrm{dL}(5.17 \mathrm{mmol} / \mathrm{L})$; triglycerides $<180 \mathrm{mg} / \mathrm{dL}(2.06 \mathrm{mmol} / \mathrm{L})$. Conversion factors: androstenedione (AD) X3.49 nmol/liter; testosterone (T) X3.47 nmol/liter; 17-hydroxy-progesterone (17OHP) X3.026 nmol/liter; estradiol X3.67 pmol/liter; and DHEAS $\mathrm{X} 2.57 \mathrm{nmol} /$ liter. $\Delta \max$ denotes the differences between peak and basal LH or FSH concentration. The dose of daily glucocorticoid was converted into milligrams of daily hydrocortisone equivalent $(1 \mathrm{mg}$ dexamethasone $=14 \mathrm{mg}$ prednisolone $=70 \mathrm{mg}$ hydrocortisone). Free testosterone index (fTI) was calculated by the ratio $347 *$ testosterone $(\mathrm{ng} / \mathrm{mL}) / \mathrm{SHBG}(\mathrm{nmol} / \mathrm{L})[31] .{ }^{\mathfrak{S}}$ Renin was measured only in SW CAH patients. ${ }^{*} P<0.05$ versus baseline.

(1.5-9.3 IU/L) in all patients at baseline and in all but one patient at follow-up. Basal FSH levels were elevated in three patients at baseline (17.6\%) and normal in all patients at follow-up.

GnRH stimulation induced an adequate increase in LH in all but one patient at baseline (5.9\%) and in all but two patients (11.8\%) at follow-up. FSH failed to increase sufficiently by $\mathrm{GnRH}$ stimulation in two patients at baseline and at follow-up (11.8\%).

Three patients $(18 \%)$ showed TART in testicular ultrasound with a size of $6-11 \mathrm{~mm}$. In one patient TART regressed and was not detected after 2 years. In a subset of patients (6 of the 17 patients) we were able to perform a semen analysis, which showed a pathological status.

Patients with an $\mathrm{AD} / \mathrm{T}$ ratio below 0.2 , indicating sufficient adrenal suppression and a testosterone of testicular origin, showed significant lower 17-OHP and AD levels than patients with an $\mathrm{AD} / \mathrm{T}$ ratio $>0.2$ (Table 3 ). Significantly more patients with an $\mathrm{AD} / \mathrm{T}$ ratio $<0.2$ received dexamethasone. Basal LH and FSH levels as well as testosterone levels were not different between the groups. However, the $\Delta$ max increase in $\mathrm{LH}$ in GnRH testing was significantly higher in the patients with an $\mathrm{AD} / \mathrm{T}$ ratio $<0.2$ than those with an $\mathrm{AD} / \mathrm{T}$ ratio $>$ 0.2 (Table 3 ). No differences in TARTs or adrenal crisis were found between the groups.

\subsection{Questionnaires}

3.4.1. General Well-Being. Analysis of the QoL questionnaires (GBB-24, HADS, and SF-36) revealed no significant changes in $z$-scores during the 2 -year study period in our adult male CAH patient cohort (Figure 1). However, all dimensions of the GBB-24 showed a trend to increased $z$-scores indicating an impairment of QoL (Figure 1(a)). Similar results were found for the anxiety and depression $z$-scores of the HADS questionnaires (Figure 1(b)). $z$-scores of the SF-36 
TABLE 3: Biochemical and hormonal parameters in male patients with 21-OHD depending on AD/T ratio at study start (baseline).

\begin{tabular}{|c|c|c|}
\hline & $\mathrm{AD} / \mathrm{T}$ ratio $<0.2$ & $\mathrm{AD} / \mathrm{T}$ ratio $>0.2$ \\
\hline BMI $\left(\mathrm{kg} / \mathrm{m}^{2}\right)$ & $25.4 \pm 5.9$ & $27.8 \pm 4.8$ \\
\hline BP systolic/diastolic (mmHg) & $120 / 79 \pm 14 / 7$ & $119 / 79 \pm 6 / 6$ \\
\hline Potassium (mmol/L) & $3.81 \pm 0.36$ & $3.68 \pm 0.55$ \\
\hline Sodium (mmol/L) & $141.2 \pm 0.9$ & $140.0 \pm 2.8$ \\
\hline Cholesterol (mg/dL) & $178 \pm 40$ & $154 \pm 22$ \\
\hline Triglycerides (mg/dL) & $106 \pm 68$ & $100 \pm 44$ \\
\hline 17-OHP (ng/mL) & $2.7 \pm 2.5$ & $35.2 \pm 16.1^{* * *}$ \\
\hline Androstenedione (ng/mL) & $0.52 \pm 0.27$ & $3.28 \pm 3.36^{*}$ \\
\hline DHEAS (ng/mL) & $425 \pm 239$ & $944 \pm 1228$ \\
\hline Testosterone (ng/mL) & $5.7 \pm 2.6$ & $4.0 \pm 2.4$ \\
\hline Free testosterone index & $47.0 \pm 12.5$ & $33.1 \pm 17.4$ \\
\hline $\mathrm{AD} / \mathrm{T}$ ratio & $0.09 \pm 0.03$ & $0.94 \pm 0.68^{* * *}$ \\
\hline Estradiol (pg/mL) & $25.5 \pm 8.3$ & $28.2 \pm 3.4$ \\
\hline LH basal (U/L) & $4.4 \pm 2.4$ & $3.6 \pm 1.9$ \\
\hline$\Delta \max \mathrm{LH}$ & $31.5 \pm 10.1$ & $18.5 \pm 8.1^{*}$ \\
\hline FSH basal (U/L) & $8.1 \pm 7.9$ & $4.5 \pm 1.3$ \\
\hline$\Delta \max F S H$ & $7.1 \pm 5.1$ & $2.8 \pm 1.9$ \\
\hline $\begin{array}{l}\text { No. of adrenal crisis during 2-year } \\
\text { follow-up }\end{array}$ & 2 & 1 \\
\hline$\%$ of patients with TART & $18 \%$ & $17 \%$ \\
\hline $\begin{array}{l}\text { daily GC equivalent dose } / \mathrm{m}^{2} \\
\mathrm{BSA}\left(\mathrm{mg} / \mathrm{m}^{2}\right)\end{array}$ & $20.5 \pm 5.7$ & $18.7 \pm 6.2$ \\
\hline $\begin{array}{l}\% \text { of patients receiving any } \\
\text { treatment regimen with } \\
\text { dexamethasone }\end{array}$ & $55 \%$ & $0 \%{ }^{*}$ \\
\hline$\%$ SW & $64 \%$ & $67 \%$ \\
\hline $\begin{array}{l}\text { Daily fludrocortisone dose } / \mathrm{m}^{2} \\
\text { BSA }\left(\mathrm{mg} / \mathrm{m}^{2}\right),{ }^{\circledR}\end{array}$ & $60.1 \pm 15.4$ & $53.5 \pm 7.1$ \\
\hline
\end{tabular}

Data are means \pm SD. BMI: body mass index; BP: blood pressure; BSA: body surface area. Normal ranges (SI units shown in brackets): sodium 134$145 \mathrm{mmol} / \mathrm{L}$; potassium 3.4-5.2 mmol/L; cholesterol < $200 \mathrm{mg} / \mathrm{dL}(5.17 \mathrm{mmol} / \mathrm{L})$; triglycerides $<180 \mathrm{mg} / \mathrm{dL}(2.06 \mathrm{mmol} / \mathrm{L})$. Conversion factors: androstenedione (AD) X3.49 nmol/liter; testosterone (T) X3.47 nmol/liter; 17-hydroxy-progesterone (17OHP) X3.026 nmol/liter; estradiol X3.67 pmol/liter; and DHEAS $\mathrm{X} 2.57 \mathrm{nmol} /$ liter. $\Delta \max$ denotes the differences between peak and basal LH or FSH concentration. The dose of daily glucocorticoid was converted into milligrams of daily hydrocortisone equivalent $(1 \mathrm{mg}$ dexamethasone $=14 \mathrm{mg}$ prednisolone $=70 \mathrm{mg}$ hydrocortisone $)$. Free testosterone index (fTI) was calculated by the ratio $347 *$ testosterone $(\mathrm{ng} / \mathrm{mL}) / \mathrm{SHBG}(\mathrm{nmol} / \mathrm{L})[31] .{ }^{\circledR}$ Only in SW CAH patients. ${ }^{*} \mathrm{P}<0.05 ;{ }^{* * *} \mathrm{P}<0.001$.

questionnaire showed a trend to impairments especially in the dimensions "physical functioning," "general health perception," and "emotional role functioning" (Figure 1(c)). The dimensions role "physical functioning" and "bodily pain" were the least impaired parameters.

3.4.2. Sexual Well-Being. The analysis of the participants' $z$ scores revealed that male $\mathrm{CAH}$ patients exhibited a slightly reduced sexual drive. More pronounced impairments were observed for the dimensions "erections" and "ejaculations," whereas the dimensions "problem assessment" and "overall satisfaction" revealed normal $z$-scores (Figure 2). No significant differences in BSFI $z$-scores were found between patients with $\mathrm{AD} / \mathrm{T}$ ratio $<0.2$ or $>0.2$.

Further analysis showed that $\mathrm{AD}$ levels significantly negatively correlated with $z$-scores of the dimension "sexual drive" ( $P<0.05$; Figure 3$)$ with higher AD levels associated with lower $z$-scores (=impaired "sexual drive").
Decreases in QoL and sexual well-being were not correlated with the presence of TARTs.

\section{Discussion}

Development of TARTs and suppression of the gonadal axis are possible factors that might cause reduced fertility in male $\mathrm{CAH}$ patients $[1,2,21]$. It is suggested that adrenal-derived androgen excess due to insufficient hormonal control might be the underlying cause $[2,3]$. A recent study in adult male $\mathrm{CAH}$ patients revealed a high prevalence of impaired Leydig cell function and impaired spermatogenesis [1]. However, the authors found no correlation between semen parameters, hormonal control, and TART prevalence or size [1].

In our current study, the majority of patients showed basal testosterone and LH within the normal range of young healthy men [10] suggesting normal Leydig cell function in most of the patients. After two years no significant 


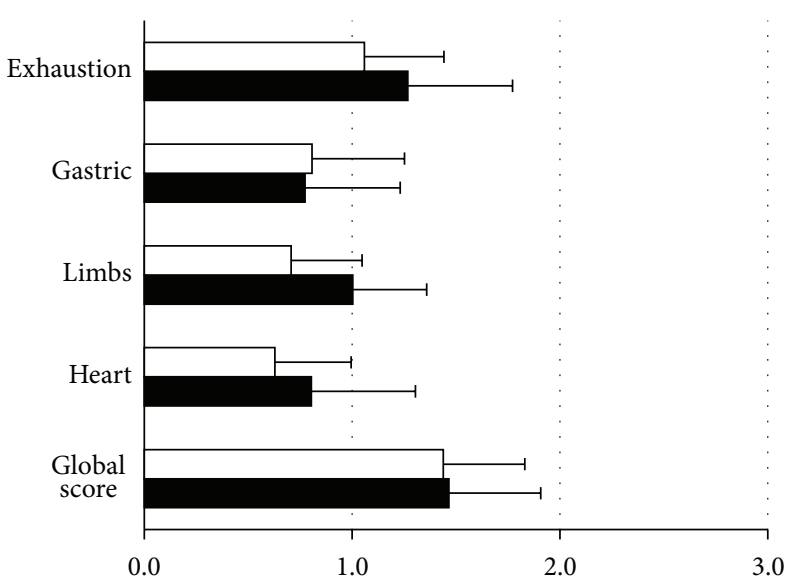

(a)

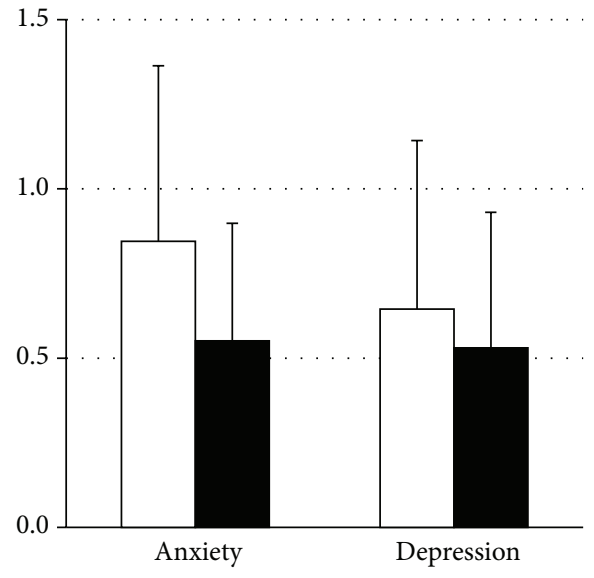

(b)

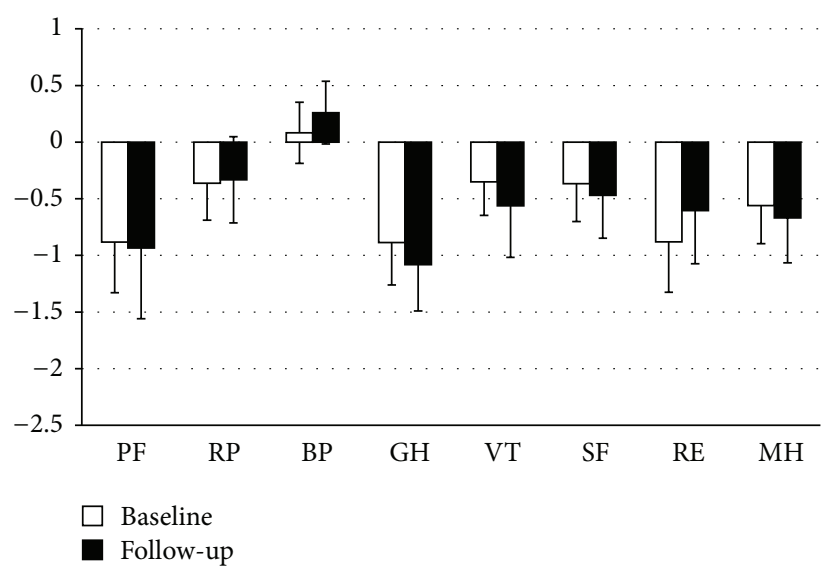

(c)

Figure 1: $z$-scores (mean \pm SEM scores) for (a) GBB-24, (b) HADS, and (c) SF-36 in male patients with congenital adrenal hyperplasia at baseline and after 2-year follow-up. Decade- and sex-adjusted $z$-scores were calculated for subgroup analysis. Higher scores indicate greater impairment of well-being, anxiety, or depression in GBB-24 and HADS. Higher scores in SF-36 indicate less pain or less impaired functioning. The respective control group has the $z$-score value 0 . Physical functioning (PF); role functioning physical (RP); bodily pain (BP); general health perception $(\mathrm{GH})$; vitality (VT); social functioning (SF); role functioning emotional (RE); mental health (MH).

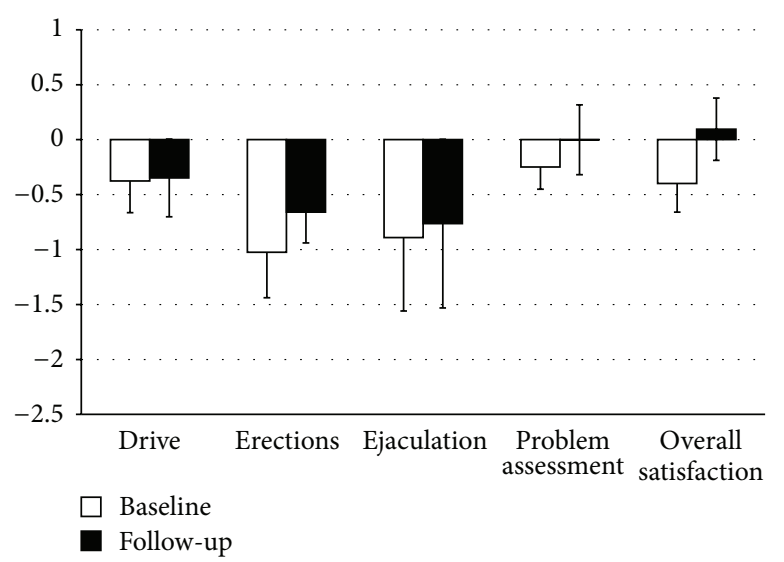

Figure 2: $z$-scores (mean \pm SEM scores) for the male Brief Sexual Function Inventory (BSFI) in male patients with congenital adrenal hyperplasia at baseline and after 2-year follow-up. Lower scores indicate higher levels of impairment. The control group has the $z$-score value 0 . 


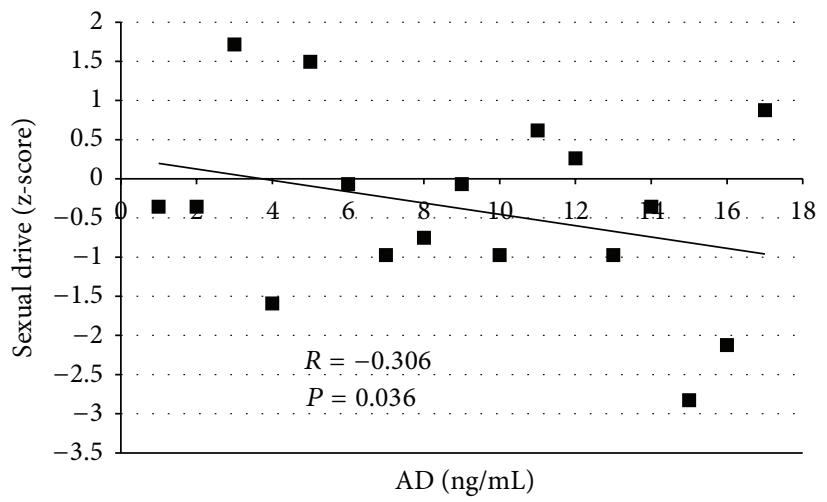

FIGURE 3: Correlation of androstenedione (AD) levels and $z$-scores of "sexual drive" of the male Brief Sexual Function Inventory (BSFI) in male patients with congenital adrenal hyperplasia at baseline. Higher scores indicate less impaired functioning.

differences were observed in our patients indicating stable therapeutic regimens. However, $\mathrm{LH}$ and FSH showed a more pronounced increase $(\Delta \max )$ after $\mathrm{GnRH}$ stimulation than reported in healthy normal males [10]. We further subdivided our cohort into a group with good hormonal control and only testicular testosterone production indicated by an androstenedione/testosterone $(\mathrm{AD} / \mathrm{T})$ ratio $<0.2$ and a group with poorer disease control and mixed adrenal and testicular testosterone production indicated by an $\mathrm{AD} / \mathrm{T}$ ratio $>0.2$ [22]. The group with an $\mathrm{AD} / \mathrm{T}$ ratio $>0.2$ showed a normal $\mathrm{LH}$ and $\mathrm{FSH}$ response ( $\Delta \max$ ) to $\mathrm{GnRH}$ compared to healthy young men [10]. However, the group with an $\mathrm{AD} / \mathrm{T}$ ratio $<0.2$ presented a significant higher $\mathrm{LH}$ response to $\mathrm{GnRH}$ testing. This resembled a prepubertal response in GnRH testing but might be also due to a suppressed hypothalamic-pituitary axis with a decreased release of $\mathrm{GnRH}$ from the hypothalamus. This might be caused by abundant adrenal androgens, which seems not to be the case in this group with $\mathrm{AD} / \mathrm{T}$ ratio $<0.2$. Another explanation might be hypothalamic suppression by glucocorticoids. Interestingly, the percentage of dexamethasone treated patients was significantly higher in the group with an $\mathrm{AD} / \mathrm{T}$ ratio $<0.2$ compared to the group with a ratio $>0.2$, but we did not find a significant difference in total daily glucocorticoid equivalent dose per body surface between the two groups. In addition, the amount of glucocorticoid used was approximately similar to that used in other recent studies with male CAH patients $[1,23]$. We assume that total glucocorticoid doses were not too high because our patients showed still normal and not suppressed LH levels. In summary, this suggests that dexamethasone has a profound effect on the hypothalamic-pituitary feedback regulation. This is in accordance with previous reports that changing glucocorticoid medication from hydrocortisone to dexamethasone resulted in an increased fertility [24].

Besides these somatic causes of impaired fertility in $\mathrm{CAH}$ males, there might be aspects of psychosocial adaption and sexual well-being which might be additional factors for impaired fertility. We investigated sexual well-being by using the male BSFI. We performed this in a prospective fashion and used also quality of life questionnaires to detect possible other changes or general influences during the 2-year study period. During the study period our CAH patients showed unchanged BMI, unchanged metabolic and hormonal parameters, and unchanged impaired $z$-scores in QoL questionnaires. Impaired QoL in male CAH patients has been shown in previous studies [7, 25-27]; however, these had only cross-sectional and not a longitudinal design. We did not find differences in QoL $z$-scores in patients that were on dexamethasone and prednisolone treatment compared to hydrocortisone only as previously reported [27]. This might be due to the rather small number of patients in our subanalysis.

As for sexual well-being, we detected that especially the dimensions "sexual drive," "erections," and "ejaculations" were impaired in our cohort. Interestingly, the dimensions "problem assessment" and "overall satisfaction" revealed normal $z$-scores. It is important to point out that "overall satisfaction" should not be confused with the mean score of the functional domains of the BSFI [18], and additional factors might be involved not covered by the questions. It is known that patients with low scores on functional domains, for example, ejaculatory impairment as a side-effect of an anti-depressant drug, do not necessarily report reduced overall sexual satisfaction [18].

We are the first to describe a clearly impaired sexual wellbeing in male $\mathrm{CAH}$ patients by using an established sexual function questionnaire. Interestingly, we observed that poor disease control, according to elevated androstenedione levels, was associated with a reduced "sexual drive." This directly links CAH therapy with the aspect of sexual well-being. Therefore, we believe that aspects of psychosocial adaption and sexual well-being might be important additional factors for impaired fertility in our male CAH patients.

There might be additional factors for lower fecundity in male CAH patients. First, $\mathrm{CAH}$ patients have had a chronic disease since their childhood, as well as having been exposed to exogenous glucocorticoids also during pubertal development. Secondly, male CAH patients have still a lower height than the average male population [28] and this might cause problems in psychosocial adaptation. However, a recent Hungarian study showed that sexual activity was not clearly related to other anthropometric parameters such as height [29]. 
Possible limitations of our study are as follows. (1) There is no normative data for Germany for calculating $z$-scores for the BSFI, and we had to rely on normative data from Norway. However, no significant differences in functional BSFI scores were found between the Norwegian data and American data from the Olmsted County [18]. (2) There is increasingly reduced sexual function concerning drive, erection, ejaculation, and problem assessment with age with most of these age-related effects starting at $>50$ years old [18]. However, our patients were all below the age of $50 \mathrm{y}$. (3) Our study is a rather small cohort of male $\mathrm{CAH}$ patients; however, this is the first longitudinal study in adult male CAH patients.

In conclusion, we showed that male $\mathrm{CAH}$ patients with a normal $\mathrm{AD} / \mathrm{T}$ ratio showed an increased $\mathrm{LH}$ and $\mathrm{FSH}$ response in $\mathrm{GnRH}$ testing indicating possible decreased hypothalamic GnRH release by glucocorticoid therapy. Secondly, we found that male CAH patients had impaired sexual well-being, especially regarding erections, ejaculations, and sexual drive. This might be an additional factor for reduced fecundity in adult CAH male patients.

\section{Conflict of Interests}

The authors declare that there is no conflict of interests regarding the publication of this paper.

\section{Acknowledgments}

The authors are indebted to Kathrin Zopf and Christiane Friedrich, from the Clinical Endocrinology, Charité Campus Mitte, Charité University Medicine Berlin, for their help with the patients' files and questionnaires.

\section{References}

[1] N. Reisch, M. Scherr, L. Flade et al., "Total adrenal volume but not testicular adrenal rest tumor volume is associated with hormonal control in patients with 21-hydroxylase deficiency," The Journal of Clinical Endocrinology \& Metabolism, vol. 95, no. 5, pp. 2065-2072, 2010.

[2] N. M. M. L. Stikkelbroeck, B. J. Otten, A. Pasic et al., "High prevalence of testicular adrenal rest tumors, impaired spermatogenesis, and Leydig cell failure in adolescent and adult males with congenital adrenal hyperplasia," The Journal of Clinical Endocrinology \& Metabolism, vol. 86, no. 12, pp. 57215728, 2001.

[3] J. P. Bercovici, J. Fiet, L. Gibault et al., “Testicular adrenal rest tumours in salt wasting congenital adrenal hyperplasia (in vivo and in vitro studies)," The Journal of Steroid Biochemistry \& Molecular Biology, vol. 93, no. 1, pp. 67-72, 2005.

[4] M. P. O’Leary, F. J. Fowler, W. R. Lenderking et al., "A brief male sexual function inventory for urology," Urology, vol. 46, no. 5, pp. 697-706, 1995.

[5] P. W. Speiser, R. Azziz, L. S. Baskin et al., "Congenital adrenal hyperplasia due to steroid 21-hydroxylase deficiency: an Endocrine Society clinical practice guideline," The Journal of Clinical Endocrinology \& Metabolism, vol. 95, no. 9, pp. 41334160, 2010.

[6] U. Ambroziak, T. Bednarczuk, M. Ginalska-Malinowska et al., "Congenital adrenal hyperplasia due to 21-hydroxylase deficiency-management in adults," Endokrynologia Polska, vol. 61, no. 1, pp. 142-155, 2010.

[7] N. Reisch, S. Hahner, B. Bleicken et al., "Quality of life is less impaired in adults with congenital adrenal hyperplasia because of 21-hydroxylase deficiency than in patients with primary adrenal insufficiency," Clinical Endocrinology, vol. 74, no. 2, pp. 166-173, 2011.

[8] M. C. F. Caldato, V. T. Fernandes, and C. E. Kater, "One-year clinical evaluation of single morning dose prednisolone therapy for 21-hydroxylase deficiency," Arquivos Brasileiros de Endocrinologia e Metabologia, vol. 48, no. 5, pp. 705-712, 2004.

[9] S. A. Rivkees and J. D. Crawford, "Dexamethasone treatment of virilizing congenital adrenal hyperplasia: the ability to achieve normal growth," Pediatrics, vol. 106, no. 4, pp. 767-773, 2000.

[10] M. Christ-Crain, C. Meier, P. R. Huber, L. Zimmerli, and B. Mueller, "Value of gonadotropin-releasing hormone testing in the differential diagnosis of androgen deficiency in elderly men," The Journal of Clinical Endocrinology \& Metabolism, vol. 90, no. 3, pp. 1280-1286, 2005.

[11] J. E. Ware Jr. and C. D. Sherbourne, "The MOS 36-item shortform health survey (SF-36): I. Conceptual framework and item selection," Medical Care, vol. 30, no. 6, pp. 473-483, 1992.

[12] G. Németh, "Health related quality of life outcome instruments," European Spine Journal, vol. 15, no. supplement 1, pp. S44-S51, 2006.

[13] A. Garratt, L. Schmidt, A. Mackintosh, and R. Fitzpatrick, "Quality of life measurement: bibliographic study of patient assessed health outcome measures," British Medical Journal, vol. 324, no. 7351, pp. 1417-1419, 2002.

[14] A. S. Zigmond and R. P. Snaith, "The hospital anxiety and depression scale," Acta Psychiatrica Scandinavica, vol. 67, no. 6, pp. 361-370, 1983.

[15] E. Brahler, J. Schumacher, and C. Brahler, "First all-Germany standardization of the brief form of the Gissen Complaints Questionnaire GBB-24," Psychotherapie Psychosomatik Medizinische Psychologie, vol. 50, no. 1, pp. 14-21, 2000.

[16] A. Hinz and E. Brähler, "Normative values for the hospital anxiety and depression scale (hads) in the general german population," Journal of Psychosomatic Research, vol. 71, no. 2, pp. 7478, 2011.

[17] A. Hinz, E. Brähler, R. Schwarz, J. Schumacher, and A. Stirn, "How useful is the calculation of total scores for questionnaires concerning health related quality of life?" Psychotherapie Psychosomatik Medizinische Psychologie, vol. 55, no. 3-4, pp. 221228, 2005.

[18] A. Mykletun, A. A. Dahl, M. P. O’Leary, and S. D. Fosså, “Assessment of male sexual function by the Brief Sexual Function Inventory," BJU International, vol. 97, no. 2, pp. 316-323, 2006.

[19] N. Reisch, M. Willige, D. Kohn et al., "Frequency and causes of adrenal crises over lifetime in patients with 21-hydroxylase deficiency," European Journal of Endocrinology, vol. 167, no. 1, pp. 35-42, 2012.

[20] S. Hahner, M. Loeffler, B. Bleicken et al., "Epidemiology of adrenal crisis in chronic adrenal insufficiency: the need for new prevention strategies," European Journal of Endocrinology, vol. 162, no. 3, pp. 597-602, 2010.

[21] H. L. Claahsen-van der Grinten, B. J. Otten, S. Takahashi et al., "Testicular adrenal rest tumors in adult males with congenital adrenal hyperplasia: evaluation of pituitary-gonadal function before and after successful testis-sparing surgery in eight patients," The Journal of Clinical Endocrinology \& Metabolism, vol. 92, no. 2, pp. 612-615, 2007. 
[22] R. J. Auchus and W. Arlt, "Approach to the patient: the adult with congenital adrenal hyperplasia," The Journal of Clinical Endocrinology \& Metabolism, vol. 98, no. 7, pp. 2645-2655, 2013.

[23] H. Gleeson, J. Davis, J. Jones, E. O’Shea, and P. E. Clayton, “The challenge of delivering endocrine care and successful transition to adult services in adolescents with congenital adrenal hyperplasia: experience in a single centre over 18 years," Clinical Endocrinology, vol. 78, no. 1, pp. 23-28, 2013.

[24] H. L. Claahsen-van der Grinten, B. J. Otten, F. C. G. J. Sweep, and A. R. M. M. Hermus, "Repeated successful induction of fertility after replacing hydrocortisone with dexamethasone in a patient with congenital adrenal hyperplasia and testicular adrenal rest tumors," Fertility and Sterility, vol. 88, no. 3, pp. 705.e5-705.e8, 2007.

[25] I. Nermoen, E. S. Husebye, J. Svartberg, and K. Løvås, "Subjective health status in men and women with congenital adrenal hyperplasia: a population-based survey in Norway," European Journal of Endocrinology, vol. 163, no. 3, pp. 453-459, 2010.

[26] W. Arlt, D. S. Willis, S. H. Wild et al., "Health status of adults with congenital adrenal hyperplasia: a cohort study of 203 patients," The Journal of Clinical Endocrinology \& Metabolism, vol. 95, no. 11, pp. 5110-5121, 2010.

[27] T. S. Han, N. Krone, D. S. Willis et al., "Quality of life in adults with congenital adrenal hyperplasia relates to glucocorticoid treatment, adiposity and insulin resistance: United Kingdom Congenital adrenal Hyperplasia Adult Study Executive (CaHASE)," European Journal of Endocrinology, vol. 168, no. 6, pp. 887-893, 2013.

[28] H. Falhammar, H. F. Nyström, A. Wedell, and M. Thorén, "Cardiovascular risk, metabolic profile, and body composition in adult males with congenital adrenal hyperplasia due to 21hydroxylase deficiency," European Journal of Endocrinology, vol. 164, no. 2, pp. 285-293, 2011.

[29] I. Rurik, E. Szigethy, F. Fekete, and Z. Langmár, "Relations between anthropometric parameters and sexual activity of Hungarian men," International Journal of Impotence Research, vol. 24, no. 3, pp. 106-109, 2012.

[30] N. Krone, A. Braun, A. A. Roscher, D. Knorr, and H. P. Schwarz, "Predicting phenotype in steroid 21-hydroxylase deficiency? Comprehensive genotyping in 155 unrelated, well defined patients from southern Germany," The Journal of Clinical Endocrinology \& Metabolism, vol. 85, no. 3, pp. 1059-1065, 2000.

[31] A. Vermeulen, L. Verdonck, and J. M. Kaufman, "A critical evaluation of simple methods for the estimation of free testosterone in serum," The Journal of Clinical Endocrinology \& Metabolism, vol. 84, no. 10, pp. 3666-3672, 1999. 


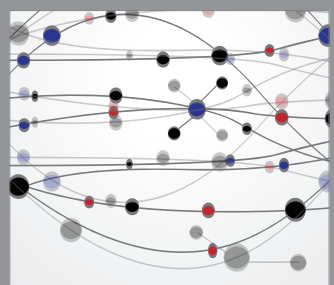

The Scientific World Journal
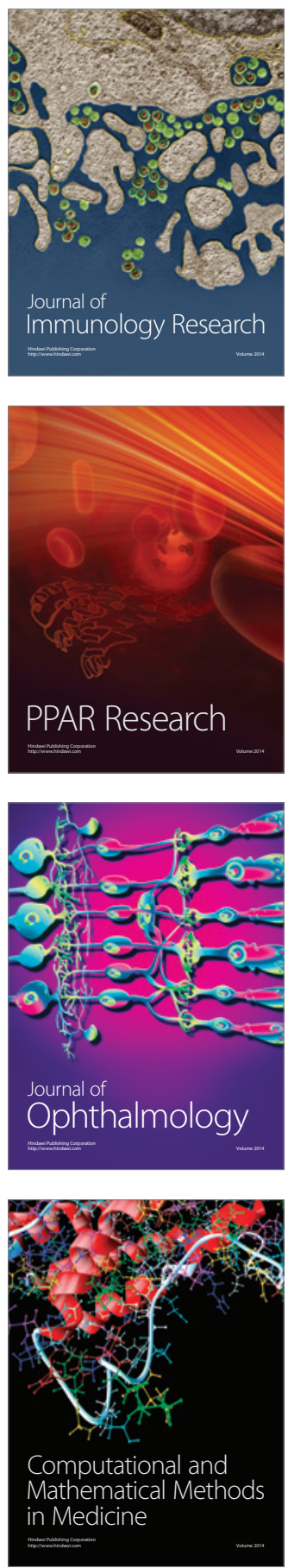

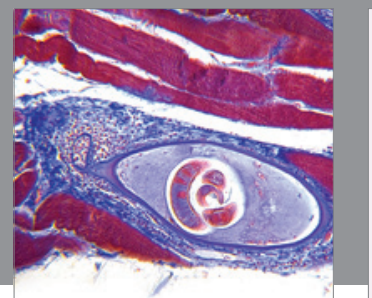

Gastroenterology

Research and Practice
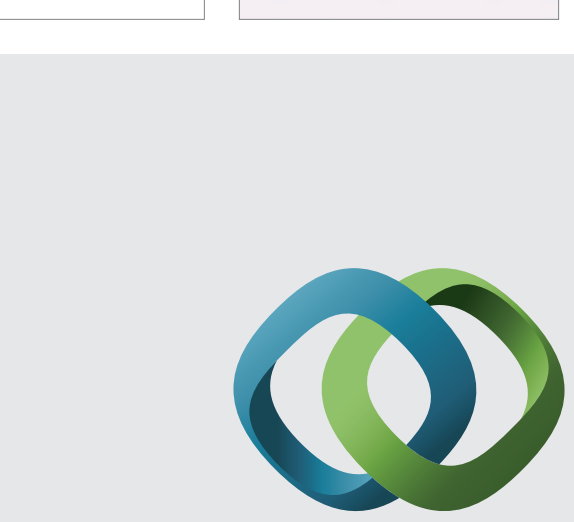

\section{Hindawi}

Submit your manuscripts at

http://www.hindawi.com
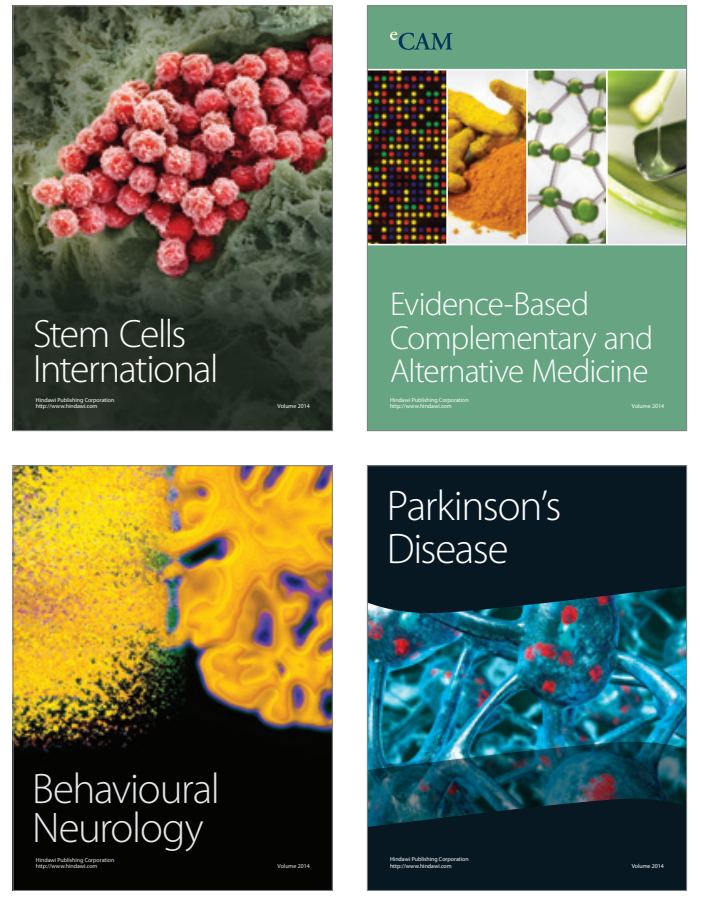
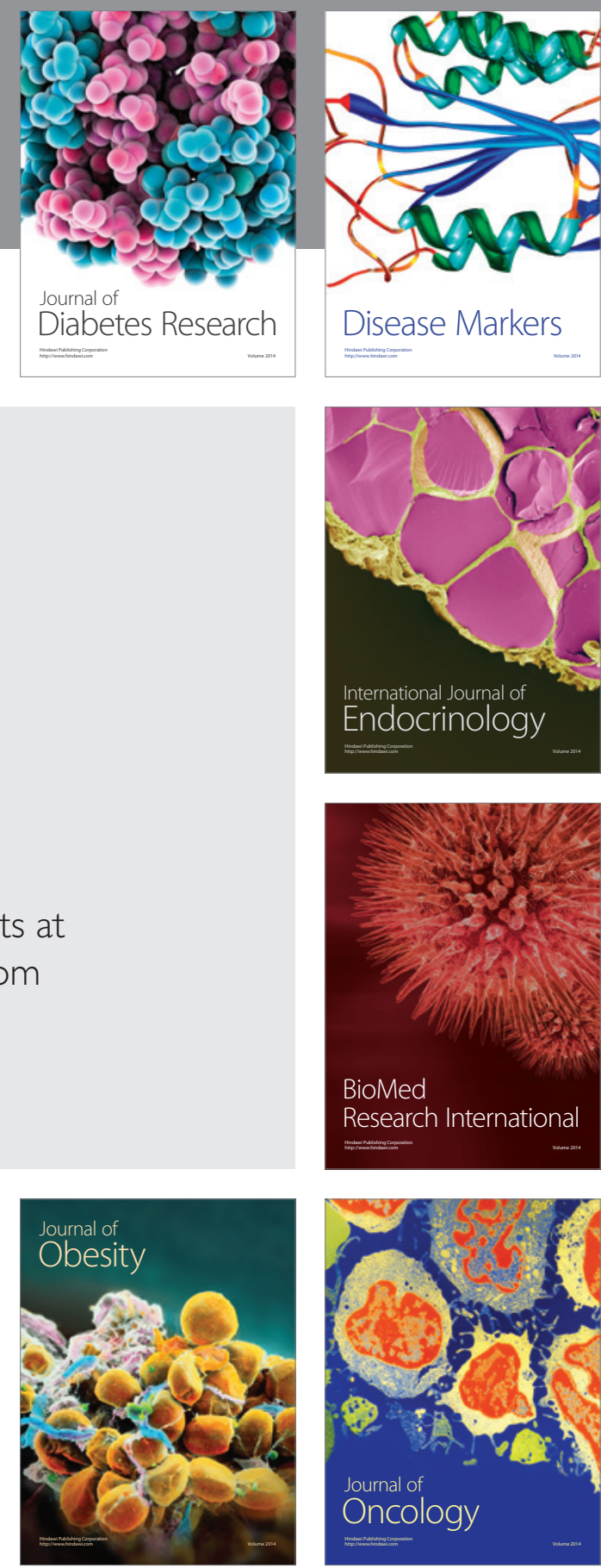

Disease Markers
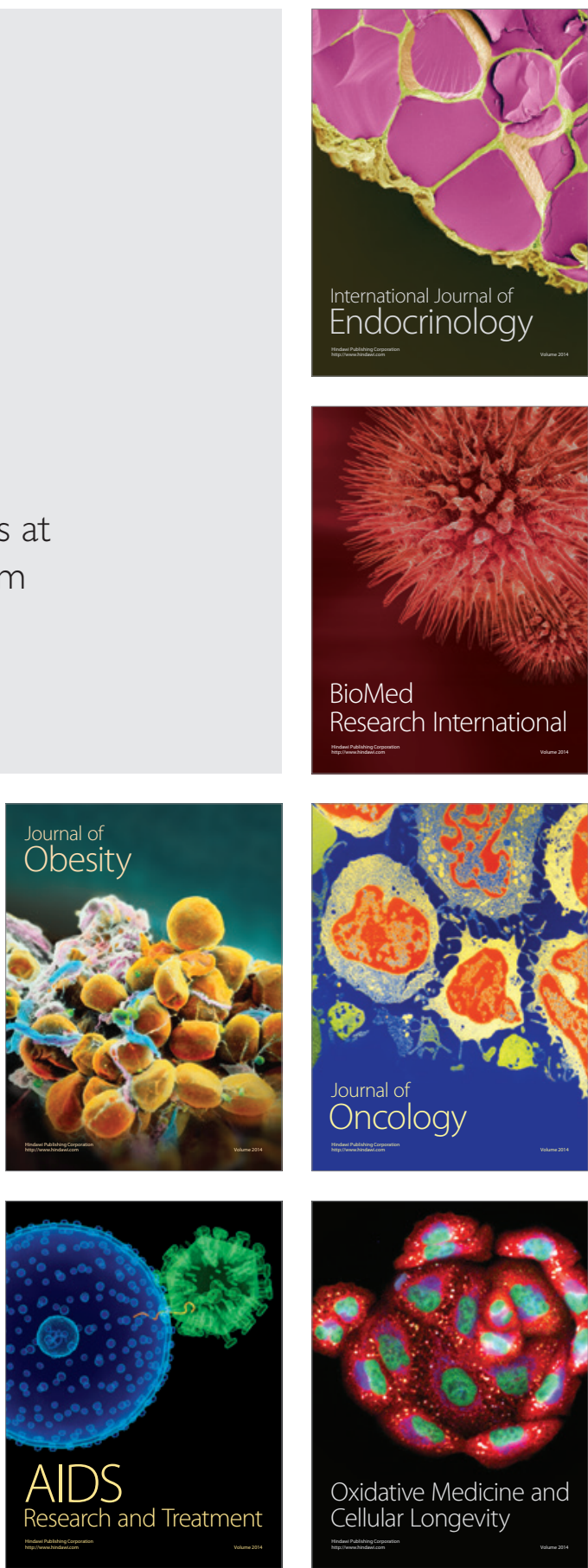